\title{
Psychometric Evaluation of Somatic and Psychological Health Report: A Sample from Chinese Adolescents
}

\author{
Ling Shi, ${ }^{1}$ Fuxiang Wu, ${ }^{2}$ Lin $\mathrm{Ye}^{3}{ }^{3} \mathrm{Gu}$ Zhu, ${ }^{4}$ Zuhong Lu, ${ }^{1}$ and Yangyang Liu ${ }^{1,4,5}$ \\ ${ }^{1}$ Research Center for Learning Sciences, Southeast University, Nanjing, Jiangsu, China \\ ${ }^{2}$ Business School, Nanjing University, Nanjing, Jiangsu, China \\ ${ }^{3}$ School of Media and Design, Shanghai Jiao Tong University, Shanghai \\ ${ }^{4}$ OIMR Berghofer Institute of Medical Research, Brisbane, Queensland, Australia \\ ${ }^{5}$ Department of Psychology, Nanjing University, Nanjing, Jiangsu, China
}

\begin{abstract}
The purpose of the present study was to do a psychometric evaluation of the somatic and psychological health report (SPHERE) among Chinese adolescents. Our participants were 116 twins (50 females). Psychometric evaluation indicated that the reliability and validity of this scale were good. The internal consistencies and split-half reliabilities of all subscales were above 0.80 . Furthermore, the item-total correlations were acceptable for all the subscales (all the values were higher than 0.20 ). The present findings suggest that the SPHERE can be well used to measure Chinese adolescents' somatic and psychological health.
\end{abstract}

Keywords: SPHERE, Chinese, adolescents, twin

Somatic and psychological health is a hot topic in the research of adolescence. In previous research, a number of studies have investigated adolescents' somatic and psychological health by using twin samples (Boomsma et al., 2000; Hansell et al., 2012; Hettema et al., 2006; Kendler et al., 2006; Vassend et al., 2012; Wright \& Martin, 2004; Zhao et al., 2013). Among these studies, somatic and psychological health report (SPHERE) is an instrument that has been widely used to measure adolescents' somatic and psychological distress (Gillespie et al., 2000; Hansell et al., 2012; Okbay et al., 2016; Rietschel et al., 2014; Wijeratne et al., 2006). The items of the SPHERE were derived from four self-report questionnaires (the 30-item version of the General Health Questionnaire, the Neurasthenia Symptom Questionnaire, the Diagnostic Interview Schedule selfreport module for somatoform disorders, and the Schedule of Fatigue and Anergia; Wijeratne et al., 2006). There are three response choices for each item: sometimes/never (coded as zero), often (coded as one), and most of the time (coded as one). A total score of all the 34 items describes the overall mental health and well-being. The SPHERE can also yield subscale scores independently measuring somatic distress, psychological distress, affective symptoms of depression/anxiety, somatic distress, fatigue, neurasthenia, and somatization (Hickie et al., 2001). The reliability and validity of the SPHERE have been well established in Western studies (Hansell et al., 2012; Hickie et al., 2001; Rietschel et al., 2014; Wijeratne et al., 2006). However, until now, no study has examined whether this scale can be applied in Eastern adolescents or not. Therefore, the present study seeks to do a psychometric evaluation of the SPHERE by using a Chinese adolescent sample.

\section{Method}

\section{Participants and Data}

Our participants consisted of 116 twins (mean age $=$ 17.26 years, $S D=0.62$ ), who were mainly from middleclass families. Fifty-four twins were recruited in pairs and the others were singletons. Fifty twins were females. The twins were middle school or high school students in Jiangsu province, China. During the survey, the participants were asked to indicate if they had been troubled by symptoms over the past few weeks. They completed the survey on a

RECEIVED 14 November 2016; ACCEPTED 20 January 2017. First published online 20 February 2017.

ADDRESS FOR CORRESPONDENCE: Yangyang Liu, Research Center for Learning Sciences, Southeast University, Nanjing 210096, China. E-mail: liuyangyang661@sina.com 
TABLE 1

Descriptive Data

\begin{tabular}{|c|c|c|c|c|c|c|c|}
\hline \multicolumn{2}{|l|}{ Item } & \multirow[b]{2}{*}{ Mean } & \multirow[b]{2}{*}{$S D$} & \multicolumn{2}{|c|}{ Skewness } & \multicolumn{2}{|c|}{ Kurtosis } \\
\hline English & Chinese & & & Statistic & SE & Statistic & SE \\
\hline Headaches? & 头疼 & 0.16 & 0.49 & & & & \\
\hline Feeling irritable or cranky? & 感觉易怒、暴躁 & 0.19 & 0.46 & & & & \\
\hline Poor memory? & 记性很差 & 0.29 & 0.55 & & & & \\
\hline Pains in your arms or legs? & 感到四肢疼痛 & 0.18 & 0.49 & & & & \\
\hline Feeling nervous or tense? & 感到紧张或者不安 & 0.19 & 0.46 & & & & \\
\hline Muscle pain after activity? & 活动后感到肌肉疼痛 & 0.31 & 0.59 & & & & \\
\hline Waking up tired? & 起床时感到累 & 0.30 & 0.59 & & & & \\
\hline Rapidly changing moods? & 情绪容易波动 & 0.29 & 0.57 & & & & \\
\hline Fainting spells? & 突发性眩晕 & 0.12 & 0.44 & & & & \\
\hline Nausea? & 恶心反胃 & 0.12 & 0.39 & & & & \\
\hline Arms or legs feeling heavy? & 感觉四肢沉重 & 0.14 & 0.44 & & & & \\
\hline Feeling unhappy/depressed? & 感到不开心/绝望 & 0.20 & 0.48 & & & & \\
\hline Gas or bloating? & 腹胀 & 0.09 & 0.37 & & & & \\
\hline Fevers? & 发热 & 0.12 & 0.40 & & & & \\
\hline Back pain? & 背部疼痛 & 0.16 & 0.45 & & & & \\
\hline Needing to sleep longer? & 需要睡更长时间 & 0.53 & 0.71 & & & & \\
\hline Prolonged tiredness after activity? & 活动后感到持续的疲倦 & 0.20 & 0.50 & & & & \\
\hline Sore throats? & 喉咙痛 & 0.19 & 0.49 & & & & \\
\hline Numb or tingling sensations? & 麻木或者刺痛的感觉 & 0.12 & 0.42 & & & & \\
\hline Feeling constantly under strain? & 感觉时常处于压力之下 & 0.33 & 0.58 & & & & \\
\hline Joint pain? & 关节痛 & 0.10 & 0.35 & & & & \\
\hline Weak muscles? & 肌肉无力 & 0.13 & 0.43 & & & & \\
\hline Feeling frustrated? & 感觉挫败 & 0.18 & 0.46 & & & & \\
\hline Diarrhoea or constipation? & 腹泻或者便秘 & 0.15 & 0.46 & & & & \\
\hline Poor sleep? & 睡眠不好 & 0.36 & 0.65 & & & & \\
\hline Getting annoyed easily? & 容易生气 & 0.25 & 0.49 & & & & \\
\hline Everything getting on top of you? & 所有事都压在你身上 & 0.25 & 0.55 & & & & \\
\hline Dizziness & 头昏眼花 & 0.13 & 0.45 & & & & \\
\hline Feeling tired after rest? & 休息之后觉得累 & 0.25 & 0.55 & & & & \\
\hline Poor concentration? & 很难集中注意力 & 0.21 & 0.49 & & & & \\
\hline Tired muscles after activity? & 活动后感到肌肉疲劳 & 0.25 & 0.49 & & & & \\
\hline Feeling lost for words? & 感觉语塞, 无言以对 & 0.26 & 0.56 & & & & \\
\hline Losing confidence? & 失去信心 & 0.16 & 0.45 & & & & \\
\hline Being unable to overcome difficulties? & 没有能力克服困难 & 0.16 & 0.45 & & & & \\
\hline SPHERE & & 5.70 & 8.06 & 2.03 & 0.22 & 3.77 & 0.44 \\
\hline Somatic distress & & 1.88 & 2.56 & 1.82 & 0.22 & 3.56 & 0.44 \\
\hline Psychological distress & & 1.32 & 2.42 & 2.44 & 0.22 & 6.57 & 0.44 \\
\hline Depression/anxiety & & 2.57 & 3.75 & 1.72 & 0.22 & 2.07 & 0.44 \\
\hline Somatic distress & & 1.75 & 2.43 & 1.71 & 0.22 & 2.49 & 0.44 \\
\hline Fatigue & & 2.04 & 2.44 & 1.19 & 0.22 & 0.64 & 0.44 \\
\hline Neurasthenia & & 1.95 & 3.20 & 2.14 & 0.22 & 4.23 & 0.44 \\
\hline Somatisation & & 1.04 & 2.22 & 2.66 & 0.22 & 6.56 & 0.44 \\
\hline
\end{tabular}

computer in their schools. The questionnaire was translated and back translated from the English version by a Chinese researcher, who is good at both English and psychology. All questionnaires were returned without any missing values. This study was approved by the institutional review board and informed consent was obtained by the participants. In this study, internal consistency and splithalf reliability were used to evaluate the reliability, and itemtotal correlations were computed to examine the validity of the SPHERE.

\section{Results}

Descriptive statistics of the subscale scores and scores for each item are shown in Table 1. The analysis of reliability indicated that the internal consistencies of this scale was good (for SPHERE, $\alpha=0.97$; for somatic distress, $\alpha=0.83$; for psychological distress, $\alpha=0.89$; for depression/anxiety, $\alpha=0.94$; for somatic distress, $\alpha=0.89$; for fatigue, $\alpha=0.87$; for neurasthenia, $\alpha=0.93$; and for somatization, $\alpha=0.92$ ). The split-half reliabilities were good as well (for SPHERE, $\alpha=0.96$; for somatic distress, $\alpha=0.82$; for psychological distress, $\alpha=0.89$; for depression/anxiety, $\alpha=0.93$; for somatic distress, $\alpha=0.88$; for fatigue, $\alpha=0.85$; for neurasthenia, $\alpha=0.94$; and for somatization, $\alpha=0.94$ ). The validities of the SPHERE were tested by using the item-total correlations (Hubel et al., 2008). The results indicated that the item-total correlations were acceptable for all the subscales of the SPHERE (all the values were higher than 0.20).

\section{Discussion}

In previous research, the SPHERE has been widely used in Western studies (Gillespie et al., 2000; Hansell et al., 2012; Okbay et al., 2016; Rietschel et al., 2014; Wijeratne et al., 2006). The present study contributes to the literature by 
examining the reliability and validity of the SPHERE in Chinese adolescents. Similar to the findings in Western studies (Hansell et al., 2012; Wijeratne et al., 2006), our data indicated that the Chinese version of the SPHERE has a good reliability and validity as well. In China, few instruments have been developed to measure adolescents' somatic and psychological distress. The Chinese version of the SPHERE provides a useful tool for researchers, who are interested in investigating Chinese adolescents' somatic and psychological health. The SPHERE has some advantages over some other Chinese scales on adolescents' health. For instance, it is a short scale but can provide a lot of information on several kinds of symptoms at one measurement. Furthermore, it can provide continuous data rather than binary or ordinal data, which is easier for genetic modeling in twin research (Hansell et al., 2012). In sum, our study suggests that the SPHERE is a good tool and can be well used to measure adolescents' somatic and psychological health.

\section{Acknowledgments}

We are grateful for the support from the National Natural Science Fund of China (31301027), the 12th Five Year Plan of Jiangsu Education (B-a/2015/01/001), the National Social Science Fund Major Projects (14ZDA024), Open Project Program of Key Laboratory of Child Development and Learning Science of Ministry of Education, Southeast University (No.CDLS-2016-02).

\section{References}

Boomsma, D. I., Beem, A. L., van den Berg, M., Dolan, C. V., Koopmans, J. R., Vink, J. M., ... Slagboom, P. E. (2000). Netherlands Twin Family Study Of Anxious Depression (NETSAD). Twin Research, 3, 323-334.

Gillespie, N. A., Zhu, G., Heath, A. C., Hickie, I. B., \& Martin, N. G. (2000). The genetic aetiology of somatic distress. Psychological Medicine, 30, 1051-1061.

Hansell, N. K., Wright, M. J., Medland, S. E., Davenport, T. A., Wray, N. R., ... Hickie, I. B. (2012). Genetic co-morbidity between neuroticism, anxiety/depression and somatic distress in a population sample of adolescent and young adult twins. Psychological Medicine, 42, 1249-1260.
Hettema, J. M., Neale, M. C., Myers, J. M., Prescott, C. A., \& Kendler, K. S. (2006). A population-based twin study of the relationship between neuroticism and internalizing disorders. American Journal of Psychiatry, 163, 857-864.

Hickie, I. B., Davenport, T. A., Hadzi-Pavlovic, D., Koschera, A., Naismith, S. L., Scott, E. M., \& Wilhelm, K. A. (2001). Development of a simple screening tool for common mental disorders in general practice. Medical Journal of Australia, 175, S10-S17.

Hubel, M., Hagell, P., \& Sivberg, B. (2008). Brief report: Development and initial testing of a questionnaire version of the Environmental Rating Scale (ERS) for assessment of residential programs for individuals with autism. Journal of Autism and Developmental Disorders, 38, 1178-1183.

Kendler, K. S., Gatz, M., Gardner, C. O., \& Pedersen, N. L. (2006). Personality and major depression - A Swedish longitudinal, population-based twin study. Archives of General Psychiatry, 63, 1113-1120.

Okbay, A., Baselmans, B. M. L., De Neve, J.-E., Turley, P., Nivard, M. G., Fontana, M. A. et al. (2016). Genetic variants associated with subjective well-being, depressive symptoms, and neuroticism identified through genome-wide analyses. Nature Genetics, 48, 624-633.

Rietschel, L., Zhu, G., Kirschbaum, C., Strohmaier, J., Wüst, S., Rietschel, M., \& Martin, N. G. (2014). Perceived stress has genetic influences distinct from neuroticism and depression. Behavior Genetics, 44, 639-645.

Vassend, O., Roysamb, E., \& Nielsen, C. S. (2012). Neuroticism and self-reported somatic health: A twin study. Psychology \& Health, 27, 1-12.

Wijeratne, C., Hickie, I., \& Davenport, T. (2006). Is there an independent somatic symptom dimension in older people?. Journal of Psychosomatic Research, 61, 197-204.

Wright, M. J., \& Martin, N. G. (2004). Brisbane adolescent twin study: Outline of study methods and research projects. Australian Journal of Psychology, 56, 65-78.

Zhao, J., Goldberg, J., \& Vaccarino, V. (2013). Promoter methylation of serotonin transporter gene is associated with obesity measures: A monozygotic twin study. International Journal of Obesity, 37, 140-145. 